\title{
Bot-teachers in hybrid massive open online courses (MOOCs): A post-humanist experience
}

\author{
Aras Bozkurt \\ Anadolu University, Turkey \\ Whitney Kilgore \\ University of North Texas, USA \\ Matt Crosslin \\ University of Texas, Arlington, USA
}

\begin{abstract}
Networked technologies have created many learning opportunities and led to new learning models such as massive open online courses (MOOCs). However, MOOCs are an evolving learning model that are even today changing according to learners' needs. First generation cMOOCs and second generation xMOOCs are now being followed by third generation hybrid MOOCs. In these evolution cycles, there are many experimental practices such as the use of bot-teachers. This study examines and explains hybrid MOOCs and then focuses on the use of bot-teachers within a post-humanist perspective, using teaching presence from the community of inquiry (CoI) and actor-network theory (ANT) as theoretical lenses. The research findings reveal that, while the use of bot-teachers is promising and beneficial in terms of facilitating and increasing discourse, it is ineffective in providing other components of teaching presence such as direct instruction, and/or design and organisation. However, analysis found that the use of bot-teachers is very helpful in increasing interaction within a learning community and can be used as an assistant during the teaching/learning process. Additionally, learners' positive behaviours indicate that botteachers seem to be working in some respects, indicating that they still hold promise as an educational tool.
\end{abstract}

\section{Introduction}

The advent of Web 2.0, and information and communication technologies (ICT) affected many aspects of modern life, including social learning in digital distributed networks. The learning opportunities that emerged with Web 2.0 also revealed the significance of openness as a vital component of the online learning practices. According to Weller (2014), Web 2.0 was significant for open education in two aspects. Firstly, it decentralised content and created a culture of openness. Secondly, it created a context where open and free were seen as the default characteristics of online material. Consequently, open education has stopped being a peripheral and begun to occupy a place in the mainstream of academic practice.

Openness has a direct relation with lifelong learning as it eliminates some barriers between lifelong learners and information sources. In addition to increasing access to information, openness has philosophical underpinnings. For instance, considering that information, created with a collective effort, is a human commodity (Stiglitz, 1995, 1999), everyone should have the right to access, process, and use information for learning purposes (Bozkurt, 2014). Though there have been many other variables that preempted these developments, the main triggering event was a philosophy of openness. In today's networked globe, openness has become part of everyday life and has had a central role in education, with MOOCs being probably the best example of the ongoing transformation fueled by openness (Weller, 2014). The call for openness has also been echoed in other lifelong learning spaces, leading to a series of endeavours. For instance, open source software (OSS), open access (OA), open educational resources (OER), OpenCourseWare (OCW), and massive open online courses (MOOCs) are part of this movement towards an open, barrier-free world (Piedra, Chicaiza, Lopez, \& Tovar Caro, 2014). 


\section{MOOCs}

MOOCs are a recent development in the openness movement. They first appeared in 2008 as an innovation born out of the openness movement, when George Siemens and Stephen Downes conducted a course titled Connectivism and Connective Knowledge: CCK08 (Siemens, 2013). The first generation of MOOCs adopted connectivism as a learning theory (Siemens, 2004). The year 2011 became an even more signficant cornerstone for MOOCs. Sebastian Thrun ushered in the second generation of MOOCs by attracting more than 160,000 learners from 190 countries who enrolled in a course titled Artificial Intelligence (AI) (Bozkurt, Özdamar Keskin, \& de Waard, 2016). The newly expanded success of these second generation MOOCs caught the attention of venture capitalists and higher education institutions, in addition to becoming very popular in media. Though they had blurred borders at the beginning, to clarify and explain differences of MOOC types on a coexisting continuum, Downes (2012) distinguished first and second generation MOOCs in terms of the pedagogical approach each one used. First generation MOOCs were coined as $C M O O C$ s to refer to connectivist MOOCs while second generation MOOCs were coined as $x M O O C s$ to refer them as an extension of traditional learning approaches, extended MOOCs.

\section{Connectivist, extended, and hybrid MOOCs: Finding the right mix}

cMOOCs emphasise creation, creativity, autonomy, and social networked learning with a focus on knowledge creation and generation. On the other hand, xMOOCs emphasise a more traditional learning approach through video presentations, short quizzes, testing, and focus on knowledge duplication (Siemens, 2012). As the field matured, other innovative approaches emerged. Hybridisation, or layered, practices were developed in order to meet the diverse needs of lifelong learners. As can be seen in the MOOC timeline (Figure 1), different MOOC variants had emerged by 2013.

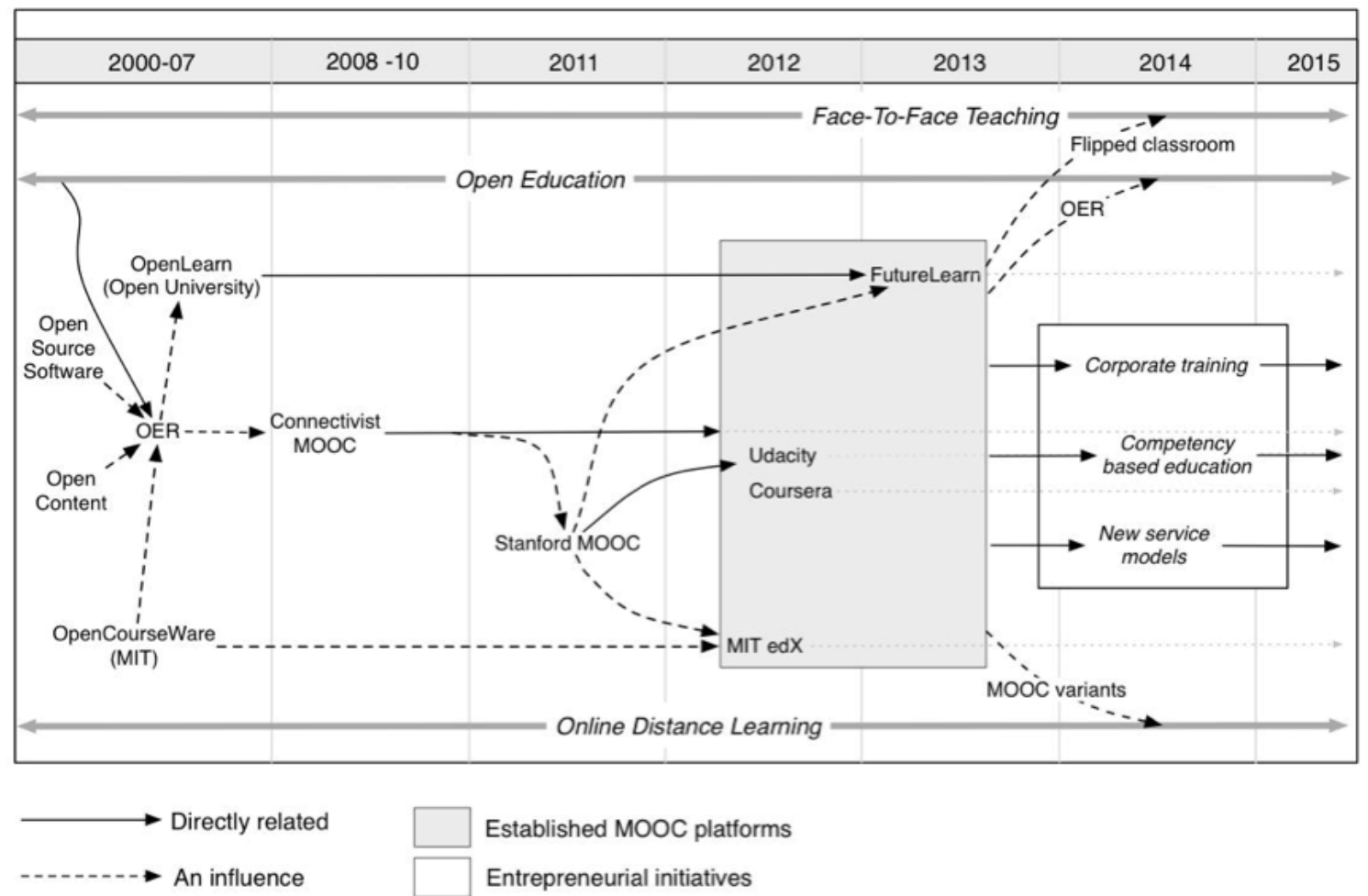

Figure 1. The MOOC timeline: Roots, triggers and evolution of MOOCs (Yuan, 2015)

MOOCs have been evolving rapidly as intermediate (hybrid or dual-layer) forms of many cMOOC and xMOOC philosophies (Freitas, Morgan, \& Gibson, 2015; Roberts, Waite, Lovegrove, \& Mackness, 2013; Waite, Mackness, Roberts, Lovegrove, 2013). They have emerged as a rich third space where the hybridisation of modes and meanings in and about higher education is proceeding rapidly (Roberts et al., 2013). As a result of this transformation in the MOOCsphere, some experimental MOOC examples have 
been created that do not neatly fit the categories of cMOOC or xMOOC. These experimental ideas can be categorised as hybrid MOOCs (Ross, Sinclair, Knox, \& Macleod, 2014).

Hybrid MOOCs are networked learning spaces in which behaviourist, cognitive, constructivist, and even connectivist pedagogies can be applied allowing MOOCers, in their learning quest, to traverse and crosspollinate among multiple paths and layers of hybrid learning ecologies (Bozkurt \& Aydin, 2015). They have sought to build on the promise of connectivist learning while providing additional support for overcoming technological barriers and the challenges of the learning centered self-determined learning; heutagogical learning (Hase, 2014; Hase \& Kenyon, 2001, 2007). The essential marker of these hybrids is a network-based course design that integrates scaffolding for technology skills and/or provides structured approaches to learning activity and social engagement (Anders, 2015). EDCMOOC, HumanMOOC and DALMOOC are some known hybrid/layered MOOCs that were executed successfully, while endeavouring to find the right mix. Hybrid MOOCs, such as EDCMOOC, tend to mix xMOOC and cMOOC experiences into one experience for all learners. Layered MOOCs (also sometimes referred to as pathway MOOCs) such as HumanMOOC and DALMOOC, tend to create two distinct learning experiences (typically one structured and one unstructured) that allow learners to mix xMOOC or cMOOC experiences into their own personal course pathway (Crosslin \& Dellinger, 2015). Throughout this study, the term hybrid MOOC was used to define a composition of cMOOCs and xMOOCs. However, readers of this article should note that the term is related to, but also differs from, the term dual-layer MOOC in related literature (Crosslin \& Wakefield, 2016).

\section{Post-humanism and bot-teachers}

Post-humanism "refuses to accept the dominance of the human over the natural-material but rather sees the human subject as produced by its material and discursive entanglements" (Bayne, 2015, p. 460). Expanding on this premise, Bayne posits that educators can essentially explore how to retain the value of teacher presence in ways that are not in opposition to some forms of automation. In other words, new technological advances would not replace teachers just because teachers are problematic or lacking in ability, but would be used to augment and assist teachers in ways that produce productive play (Bayne, 2015). The ultimate goal would not be to replace teachers with technology, but to create ways for nonhuman teachers to work in conjunction with human teachers in ways that remove all ontological hierarchies.

Within this perspective, to explore post-humanist approaches in learning processes, Botty (bot-teacher) whose name was given by the participants in EDCMOOC, was designed for an experimental use in EDCMOOC, rather than specifically supporting social, cognitive, or teaching presences. Botty operated on Twitter by searching for tweets that contained the hashtag \#edcmooc, for particular keywords. When Botty found the hashtag, it would reply by using a series of automated responses that were pre-crafted by the course facilitators. These tweets took the form of course guidance or even thought provoking utterances designed to engage the learner in discussion with the bot and with others (Bayne, Knox, Macleod, Ross, \& Sinclair, 2014). According to Bayne (2015), "as a piece of experimental boundary work, teacher bot functioned well” (p. 463). Botty elicited interesting responses from learners, including profound responses related to course concepts, misunderstandings of the generated responses, and even intentional boundary pushing by some learners seeking to see how far the bot could push its own limits.

\section{Purpose of the research}

Interaction is an important component in online networked learning spaces. As a vital component of social learning (Vygotsky, 1978), there are three types of interactions in online learning spaces: learnerlearner, learner-teacher, and learner-content interaction (Moore, 1989). However, the affordances of technology made possible a fourth type of interaction known as human-computer. In a three-level interaction framework, Hirumi (2006) defined level-II interactions that occur between the learner and human and non-human resources.

Similar to interaction theories and frameworks, learning theories of the digital age such as connectivism, have accepted both human and non-human interaction. According to connectivism, learning may reside in non-human appliances (Siemens, 2004). Accordingly, learning is viewed as a process of developing 
networks and connections among people, information, and digital learning artefacts within a ubiquitous network (Wang, Anderson, Chen, \& Barbera, 2016).

This study aims to examine human-computer interaction within a post-humanist perspective through the lenses of teaching presence from the community of inquiry (CoI) framework, as well as actor network theory (ANT). In this context, this study seeks answers to the following research questions:

- What is the interaction pattern among the learners and bot-teachers?

- How does a bot-teacher serve in a networked learning space within a teaching presence perspective?

- How do learners perceive the existence of a bot-teacher, and how do they react and communicate with it?

\section{Theoretical background}

Originally derived from Dewey's (1938) concept of transaction, interaction is a vitally important, complex and multi-faceted component of any type of learning practice (Anderson, 2003; Moore, 1989). As a concept, interaction is not limited to between human beings, but it also refers to interaction between human and non-human entities (Wagner, 1994). For an effective and efficient learning experience, it should be understood by instructors, administrators, and learning designers, how the technology employed would aid interaction and which type of interaction it would promote (Beldarrain, 2006). In this context, the research uses two theoretical lenses to further examine interaction in hybrid MOOCs: CoI and ANT.

\section{Col and teaching presence}

In the CoI framework, presence is the key factor providing deep, meaningful, and active learning in an online milieu. Accordingly, learning occurs within the community through the interaction of three core elements: cognitive, social, and teaching presence (Garrison, Anderson, \& Archer, 2000, 2001). These three presence types also have sub-categories that are helpful in detecting and observing the three core elements in a learning community (Table 1 ).

Table 1

Categories and indicators of CoI (Ice et al., 2007)

\begin{tabular}{lll}
\hline Elements & Categories & Indicators (examples only) \\
\hline Social presence & $\begin{array}{l}\text { Open communication } \\
\text { Group cohesion } \\
\text { Personal/affective }\end{array}$ & $\begin{array}{l}\text { Learning climate/risk-free expression } \\
\text { Group identity/collaboration } \\
\text { Self-projection/expressing emotions }\end{array}$ \\
Cognitive presence & Triggering event & Sense of puzzlement \\
& Exploration & Information exchange \\
& Integration & Connecting ideas \\
& Resolution & Apply new ideas \\
Teaching presence & Design \& Organisation & Setting curriculum \& methods \\
& Facilitating Discourse & Shaping constructive exchange \\
& Direct Instruction & Focusing and resolving issues \\
\hline
\end{tabular}

Teaching presence is defined as the design, facilitation, and direction of cognitive and social processes for the purpose of realising personally meaningful and educationally worthwhile learning outcomes (Anderson, Rourke, Archer, \& Garrison, 2001). It is seen "as a significant determinant of student satisfaction, perceived learning, and sense of community" (Garrison \& Arbaugh, 2007, p. 163). This study differs from previous research, which is about teaching presence and interaction among humanhuman elements of learning environments, in that it has a focus on teaching presence within humancomputer interaction by investigating the effectiveness of bot-teachers in the connectivist areas of hybrid MOOCs. 


\section{Actor network theory (ANT)}

ANT focuses on the relationships between human and non-human entities (Latour, 2005). It maps relationships that are simultaneously material (between things) and semiotic (between concepts). Accordingly, material-semiotic networks come together to act as a whole.

ANT assumes that "hybrids of societies-natures, heterogeneous assemblages in which humans and nonhumans are inextricably mixed up together” (Nimmo, 2011, p.109) and have a contingent, interwoven, and dynamic relationship (Hanseth \& Monteiro, 1998). According to ANT, the social nature is made of human and non-human actors (Akrich \& Latour 1992; Brigham \& Corbett, 1997), with both having the capacity to act upon or alter the other (Law, 1984) and each other's courses of action (Durepos \& Mills, 2012). Within a MOOC perspective, ANT provides and understanding on how the social and technological dimensions are embedded in each other (Deimann, 2014).

ANT argues that no actor has inherent power (Alexander \& Silvis, 2014). Therefore, all the entities in a network, both human and non-human, should be described by the same term, which is called the principle of generalised symmetry. Based on this view, ANT defines human and non-human entities as actants and assumes that actors in a network take the shape that they do by virtue of their relations with one another (STSwiki, 2011). In networked learning spaces, such as MOOCs, both hard and soft technologies that exist in learning processes can be assumed as actants. For example, in addition to learners and instructors, computers, multimedia services, both online and offline environments, and bots (as in this case) can be assumed as actors, all of which have unique roles in learning processes.

According to ANT, networks are the integration of the material and semiotic environments (Latour, 2009). ANT has focused on the heterogeneous complexion of networks and the way these are assembled to build actors and promote action (Murdoch, 1998). ANT claims that space is constructed within networks, and time is also forged within network colorations (Latour, 1987). Time and space are folded into complex geometries and topologies by series of connections and disconnections. There is no one time or space, rather there are a number of co-existing space-times. Networks draw together materials, which have their own space-times, into new configurations which, to some extent, reflect the types of relationships established in the network (ie., networks and spaces are generated together) (Murdoch, 1998). These arguments neatly fit to online learning networks and connectivist learning which inspired MOOCs and many other open practices. In connectivism (Siemens, 2004), networks, with all their actants, impact what we learn and how we act based on our learning.

ANT has a focus on the interplay between actors/network and activities that produce an outcome which is (as in this research) the interaction patterns that emerge in learning networks and their reflections to learning processes. In this regard, ANT was chosen as a lens to explain dynamics between human and non-human entities. This study investigates learners' interaction with bot-teachers and identifies interaction patterns while seeking to explain how bot-teachers serve in a MOOC within an ANT perspective.

\section{Research method and design}

In this research study, both quantitative and qualitative data were utilised, therefore the study is mixed method in nature. Based on the data collection and analysis sequence, explanatory sequential mixed method design was employed. The rationale for a mixed approach is that the quantitative data and results provide a general picture of the research problem, while qualitative data collection is needed to refine, extend, or explain the general picture (Creswell, 2004). For the purposes of this study, quantitative data was analysed through social network analysis (SNA) and qualitative data was analysed through content analysis.

SNA provides powerful ways to map, summarise, and visualise networks, as well as to identify key nodes that occupy strategic locations and positions within the matrix of links (Hansen, Shneiderman, \& Smith, 2010). In SNA, networks are usually visualised in a social network diagram, where nodes are represented as points and ties are represented as lines to conceptualise and analyse the nodes (Bozkurt et al., 2015). 
These nodes and the ties amongst them may represent different types of relationships, and visualising networks based on network metrics vertically and horizontally provides intuitions and insights into the shape, size, density, sub-regions, and key locations within a network (Bozkurt et al., 2016). SNA offers an $\mathrm{x}$-ray image of the organisational structure of a community, helps users discover patterns, trends, clusters, and outliers, even in complex social networks (Hansen et al., 2010), and assists researchers to interpret relationships from the emergent patterns (De Nooy, Mrvar, \& Batagelj, 2011). Within an ecological perspective (Brown, 1999), online digital networks are organic spaces rather than synthetic structures (Bozkurt et al, 2016) and they are considered to be a learning ecology (Brown \& Adler, 2008; Pata \& Bardone, 2014). SNA is considered an appropriate research methodology to map and visualise overall network (global metrics) as well as nodes and interactions amongst them (local metrics). In this research SNA was used to map the position and identify the interaction pattern of a experimental bot used in a hybrid MOOC.

Additionally, the research employed content analysis to have a deeper insight into the conversations occurred in the network. Content analysis is a technique based on explicit rules of coding (Berelson, 1952). Content analysis can be used to make inferences, interpretations, counting, summarising, or categorisation of the different types of the content. In analysing and encoding processes of the qualitative data, using significant quotes is a technique (Orcher, 2005) to portray the participants' perspectives or bring in their voices (Creswell, 2012; Yin, 2010). Researchers can use the participants' actual words along with their account and understanding (Schreiber \& Asner-Self, 2010) to support interpretations (Krippendorff, 2004) or increase reliability and validity of the qualitative research findings. Quotes were used in this research as representations of the interpretations based on the conversations between the Botty and MOOC participants.

\section{Research context}

EDCMOOC was offered on the Coursera platform: https://www.coursera.org/course/edc. The facilitators were Sian Bayne, Jen Ross, Jeremy Knox, Christine Sinclair, and Hamish Macleod in the School of Education at the University of Edinburgh. Data was collected from the third instance of the EDCMOOC, conducted between 3 November and 7 December, 2014. A total of 10145 learners from 153 different countries joined EDCMOOC. Learners came from Europe (38\%), North America (26\%), Asia (21\%), South America (8\%), Oceania (4\%), and Africa (3\%). Based on responses to Coursera's questionnaire ( $n$ = 983), female participants constituted 57\%, while male participants constituted $43 \%$, of the EDCMOOC participants. Full-time students constituted 17\%, part-time students constituted $18 \%$, and those who were not currently students constituted 65\% of EDCMOOC participants. The distribution of education level for EDCMOOC participants was: doctorate (8\%), professional school (3\%), master's (40\%), bachelor's (32\%), associate degree (4\%), college degree (6\%), high school $(6 \%)$, primary/elementary $(0,1 \%)$ degrees, and no degree (0,1\%) (Bajaj, 2014).

First written in 2011, The Manifesto for Teaching Online (Figure 2) is an ongoing project; a living document which was designed to articulate a position about online education (Online Teaching Manifesto, 2016). The manifesto provides brief statements about dimensions of online teaching and learning. It is a collection of advocative statements; more than sentences, a synthesis of much scientific research reported in an unconventional manner. Bayne and Ross (2016) reported that:

[A]lthough there are many ways of reading the manifesto, one intention was that it be seen as productive in thinking through the design of online education and assessment something that teachers might find useful and generative. It was intended to stimulate ideas about creative online teaching, and to reimagine some of the orthodoxies and unexamined truisms surrounding the field. Each point was deliberately interpretable, and it was made open so that others could remix and rewrite it. (p. 121) 
Online can be the privileged mode. Distance is a positive principle, not a deficit. \$ Place is differently, not less, important online. \$ Text has been troubled: many modes matter in representing academic knowledge. "We should attend to the materialities of digital education. The social isn't the whole story. $\quad$ Openness is neither neutral nor natural: it creates and depends on closures. Can we stop talking about digital natives? ' Digital education reshapes its subjects. The possibility of the 'online version' is overstated. There are many ways to get it right online. 'Best practice' neglects context. * Distance is temporal, affective, political: not simply spatial. * Aesthetics matter: interface design shapes learning. Massiveness is more than learning at scale: it also brings complexity and diversity. * Online teaching need not be complicit with the instrumentalisation of education. * A digital assignment can live on. It can be iterative, public, risky, and multi-voiced. * Remixing digital content redefines authorship. Contact works in multiple ways. Facetime is over-valued. ' Online teaching should not be downgraded into 'facilitation'. ' Assessment is an act of interpretation, not just measurement. Algorithms and analytics re-code education: pay attention! A routine of plagiarism detection structures-in distrust. Online courses are prone to cultures of surveillance Visibility is a pedagogical and ethical issue. Automation need not impoverish education: we welcome our new robot colleagues. 'son't succumb to campus envy: we are the campus.

Figure 2. Manifesto for teaching online (Bayne \& Ross, 2016; Online Teaching Manifesto, 2016)

Based on the statements in the Manifesto for Teaching Online, EDCMOOC adopted a different approach from both cMOOCs and xMOOCs, and therefore it was neither an xMOOC nor a cMOOC (Ross et al., 2014), but more of a hybrid MOOC (Bozkurt \& Aydin, 2015; Waite et al., 2013). EDCMOOC, rather than using one single platform to store and deliver course content, used the Coursera platform as a conduit for the movement of participants to and from a wider social media network. The course was designed as a space to produce student generated content rather than a space to consume video-based content (Knox, 2015). The 5-week EDCMOOC engaged participants with some discourse opportunities that were designed to inform understandings of the concept of digital in education and popular culture particularly utopian and dystopian narratives as well as affirmations of and challenges to the notion of the human (Ross et al., 2014). For the learners, the main challenges were to think, create, curate, and interact with digital learning space and digital artefacts as well as with each other.

EDCMOOC was developed to challenge the transmissive pedagogical model (primarily video lecture based) that had become prevalent in Coursera MOOCs. In EDCMOOC, resources in the public domain were curated and presented to students in such a manner that they were encouraged to explore, discuss, and interpret them independently (Knox, 2014). As is common in cMOOCs, there was an emphasis on groups that were formed by learners through personal learning networks (leveraging social media) to extend learning across communities of classmates on the open web. The course was central to this network, where teacher-curated and annotated resources were made available to the community of learners, as were short films, media reports, and open-access academic papers. There were no pre-defined learning outcomes and no quizzes or tests, rather learners were invited to create a web-based digital artefact that was multimodal, while also peer reviewing three of their classmates' creations. Those who participated in this final assignment (artefact creation and peer reviews) received a passing mark and an official statement of accomplishment for the course. However, a mark of distinction was earned if the peer feedback that an individual learner received exceeded a certain threshold (Ross et al., 2014).

\section{Sampling}

This study prefers not to sample a part of a 5-week hybrid MOOC, yet to examine the whole population that was active on Twitter. The reason for following such a strategy is that examining and collecting data from whole target population helps prevent researchers from having sampling errors, thereby increasing the validity of the research findings. The sample of the research consists of 423 EDCMOOC participants and 4317 interactions that occurred throughout the 5-week MOOC.

\section{Data collecting procedure and analysis}

The study consisted of two phases of data collecting and analysis process. The first phase consists of both quantitative and qualitative data while the second phase consists of only qualitative data. The study data that included the network interactions of the MOOC participants was collected and analysed through SNA. First, learners (nodes) and their relations (ties) were analysed quantitatively, and then qualitative network graphs were created based on quantitative data. Second, learners' conversations with the bot- 
teacher were analysed using content analysis to have a broader and deeper understanding of those conversations.

\section{Reliability}

A network socio-gram for each week was created and interpreted according to the six kinds of social media network patterns proposed by Smith, Rainie, Shneiderman, and Himelboim (2014). The sociograms were interpreted and re-coded by an independent researcher with experience in SNA. To be able to calculate inter-rater agreement, the total number of agreement scores between two raters were divided by the total number of all scores (sample size) and then multiplied by 100. Accordingly, it was found that inter-rater agreement for six socio-grams was $100 \%$.

\section{Strength and limitations}

The findings of this study are limited to the connectivist side of the hybrid EDCMOOC since the botteacher was only active on the microblogging platform, Twitter, and learners were engaged with Botty only on this platform. The connectivist side of the EDCMOOC was not limited to Twitter, as there were many other social networking platforms used throughout EDCMOOC, however, it was the most active platform of all social networking sites. The research findings are also limited to those who used the \#EDCMOOC hashtag during the MOOC. In addition to these limitations, the study examines a very large volume of data that provides a holistic perspective. This is a strength of the study.

\section{Ethical considerations}

Researchers followed the Association of Internet Researchers’ (AOIR) (2012) Ethical Decision-Making and Internet Research Report to analyse research findings. Accordingly, "ethical decision-making is best approached through the application of practical judgment attentive to the specific context” (p. 2). Based on this approach, the facilitators were informed about the research and permission was granted to use Twitter data captured during the EDCMOOC. The tweets that are quoted as examples were collected from the public domain. Even though the publicly shared tweets do not have any restriction, researchers paid attention to whether the tweets contained any potentially sensitive data, or if their use or reproduction might in any way cause harm to individuals. Tweets were used after critically examining the textual content contained therein. Given that tweets are also publicly available intellectual property, the tweets were used by indicating original source and owners. Additionally, the raw data was stored for further inquiries and decided to be kept for 5 years from first collected date.

\section{Findings and discussion}

\section{What is the interaction pattern among the human and non-human entities?}

The EDCMOOC metrics based on learners and their interactions on Twitter were collected and are provided on the bottom side of Figures 5, 6, 7, 8, and 9. The first week was the densest week, with 243 nodes (learners) and 2137 ties (interactions) amongst them. There was a rapid decrease in the number of learners and interactions after the first week. The fifth week had 205 nodes and 450 ties. The data regarding nodes and ties for each week is presented in Figure 3. The change in the number learners and interactions, which was very high in the first week then decreased in the second week but continued in a more stable fashion after that, is a common issue that can be observed in many MOOCs (Jordan, 2014). 


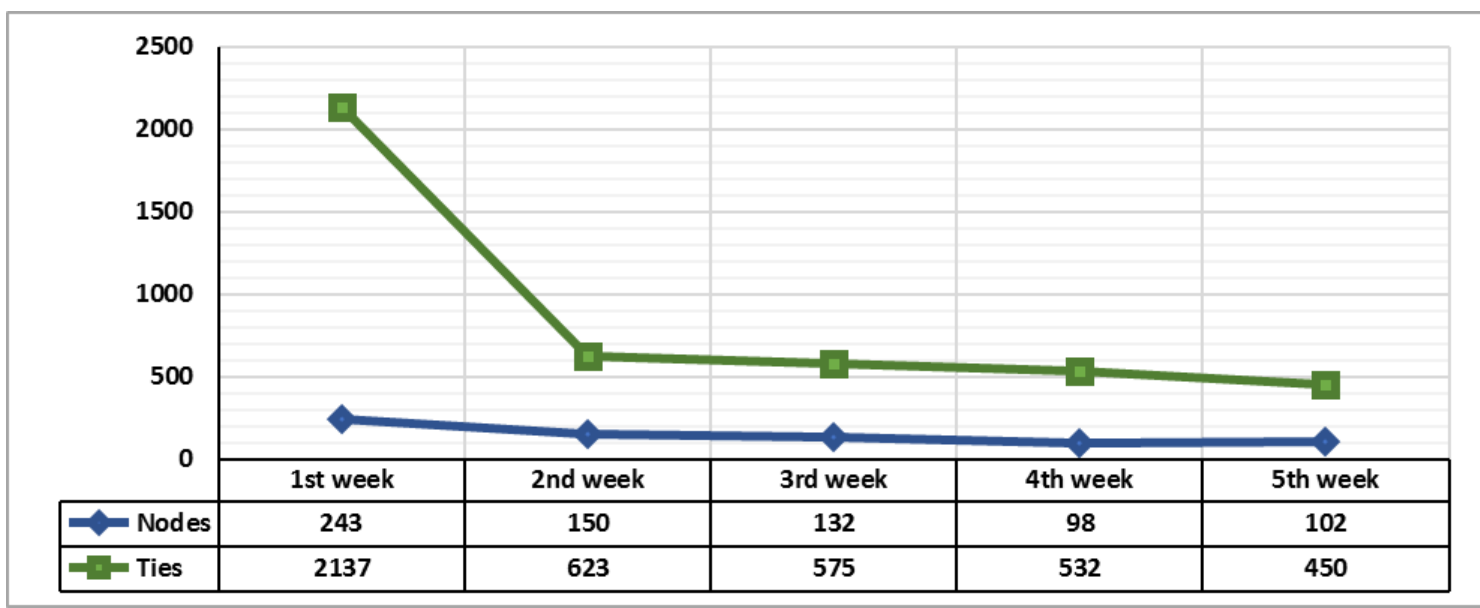

Figure 3. The change in the numbers of nodes and ties that are created among the nodes

In order to identify the bot-teacher's position in the network and community formation around it, sociograms for each week were created based on quantitative node, tie, and overall network metrics (Figure 4). As directed graphs, nodes were grouped using the Clauset-Newman-Moore cluster algorithm (Clauset, Newman, \& Moore, 2004) and the graphs were laid out using the Harel-Koren Fast Multiscale layout algorithm (Harel \& Koren, 2001). The tie colours, widths, and opacities are based on weighted tie values. The node sizes are based on betweenness centrality values.

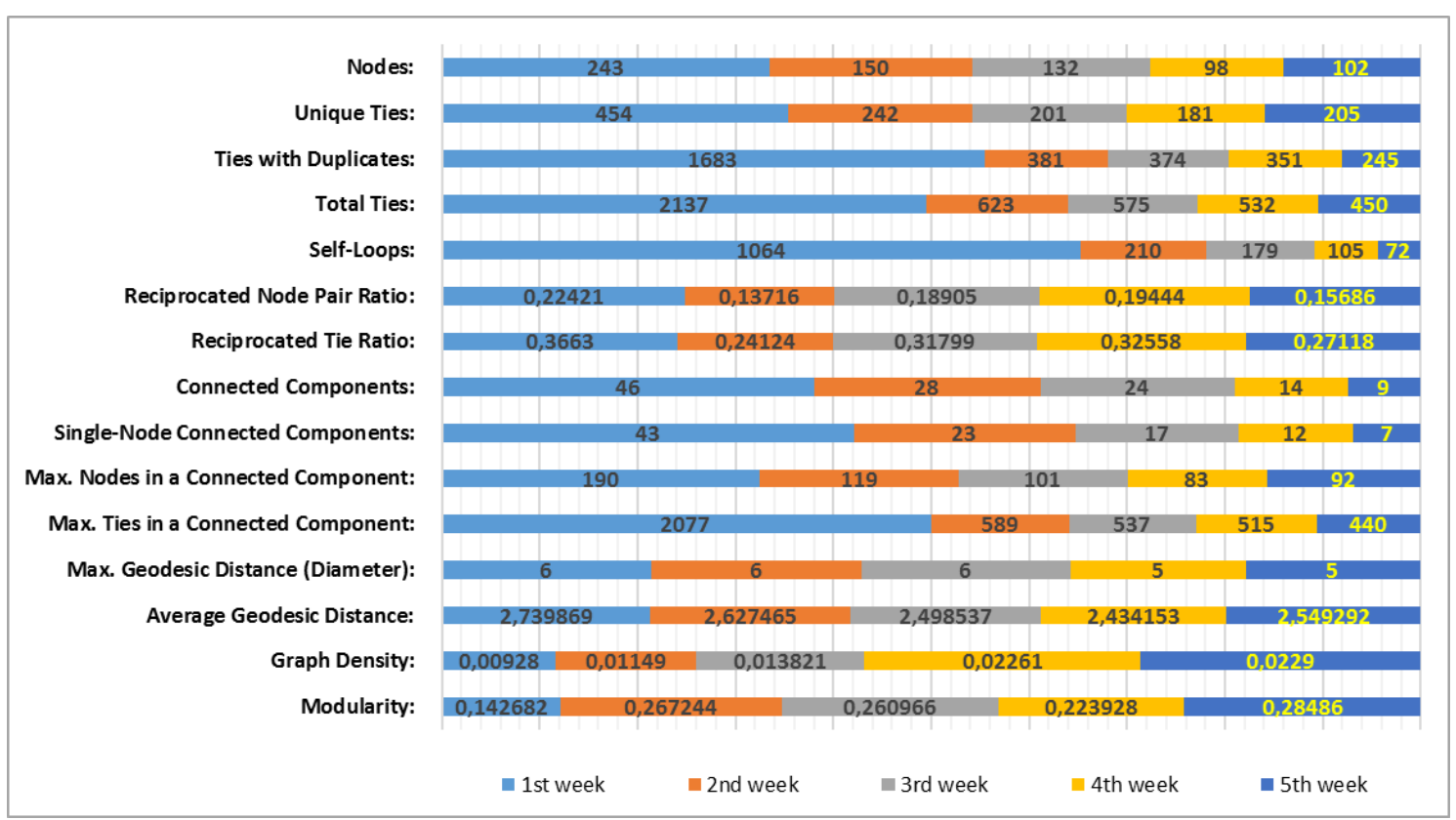

Figure 4. Network metrics of EDCMOOC for each week

Socio-grams for each week were examined and interpreted according to six types of social media network patterns (Smith et al., 2014). Accordingly, the bot-teacher and the cluster around it were identified as outhub/spoke support network. In this kind of network interaction pattern, one central hub, namely botteacher or Botty creates many outward spokes. The same pattern was observed during all the weeks of EDCMOOC community (see Figures 5, 6, 7, 8, and 9). This finding also confirms explanations proposed by ANT which highlights the social nature and relationships between both human and non-human entities. Accordingly, even though it is limited when compared to complex roles in community formation process, the bot-teacher stands as an important entity which has capacity to change and shape the network structure. 


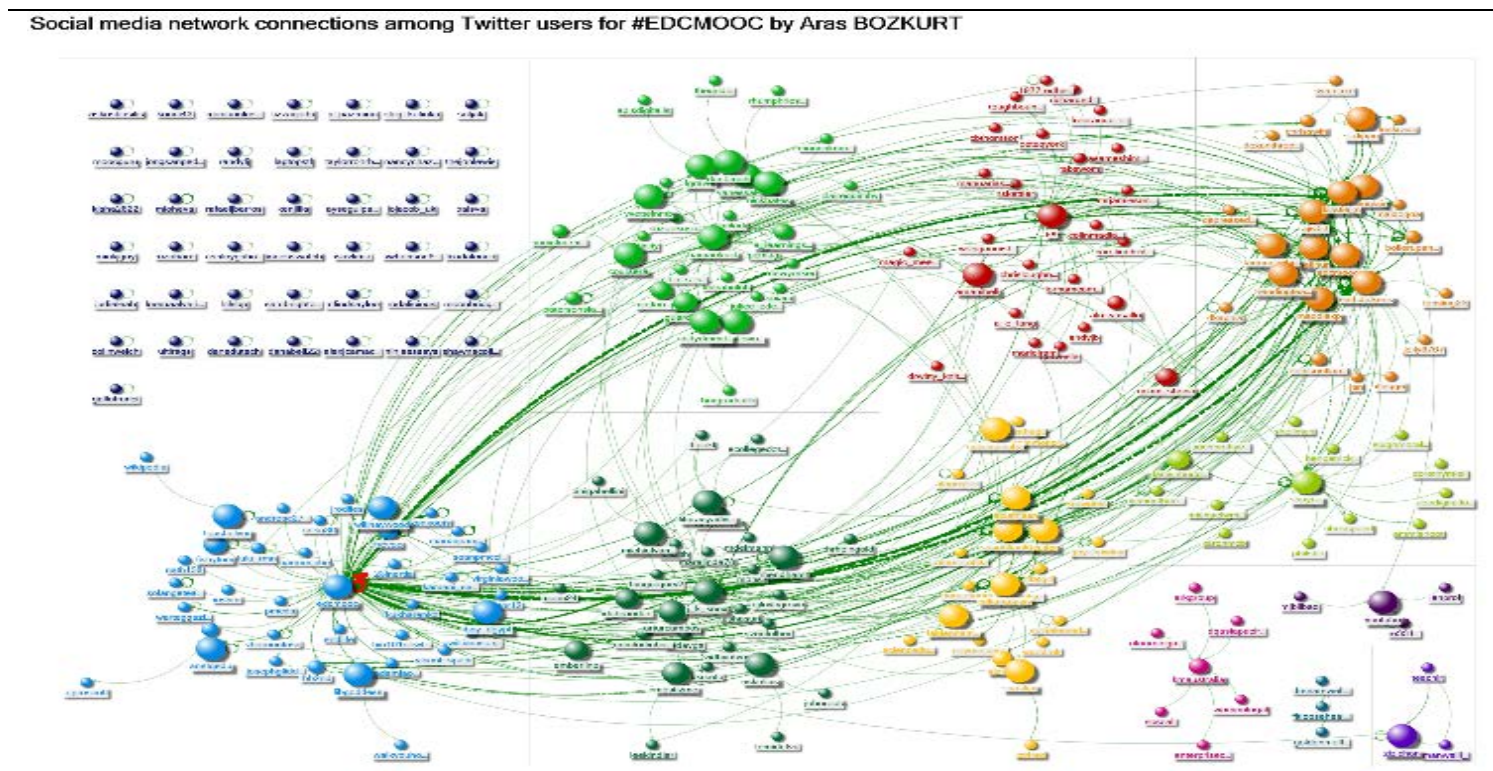

Nodes: 243

Unique ties: 454

Ties with duplicates: 1683

Total ties: 2137

Self-loops: 1064

Reciprocated node pair ratio: 0,2242152466

Reciprocated tie ratio: 0,366300366300366

Connected components: 46
Single-node connected components: 43

Max. nodes in a connected component: 190

Max. ties in a connected component: 2077

Maximum geodesic distance (diameter): 6

Average feodesic distance: 2,739869

Graph density: 0,00928476686052444

Modularity: 0,142682

Figure 5. Network metrics and socio-gram of the first week

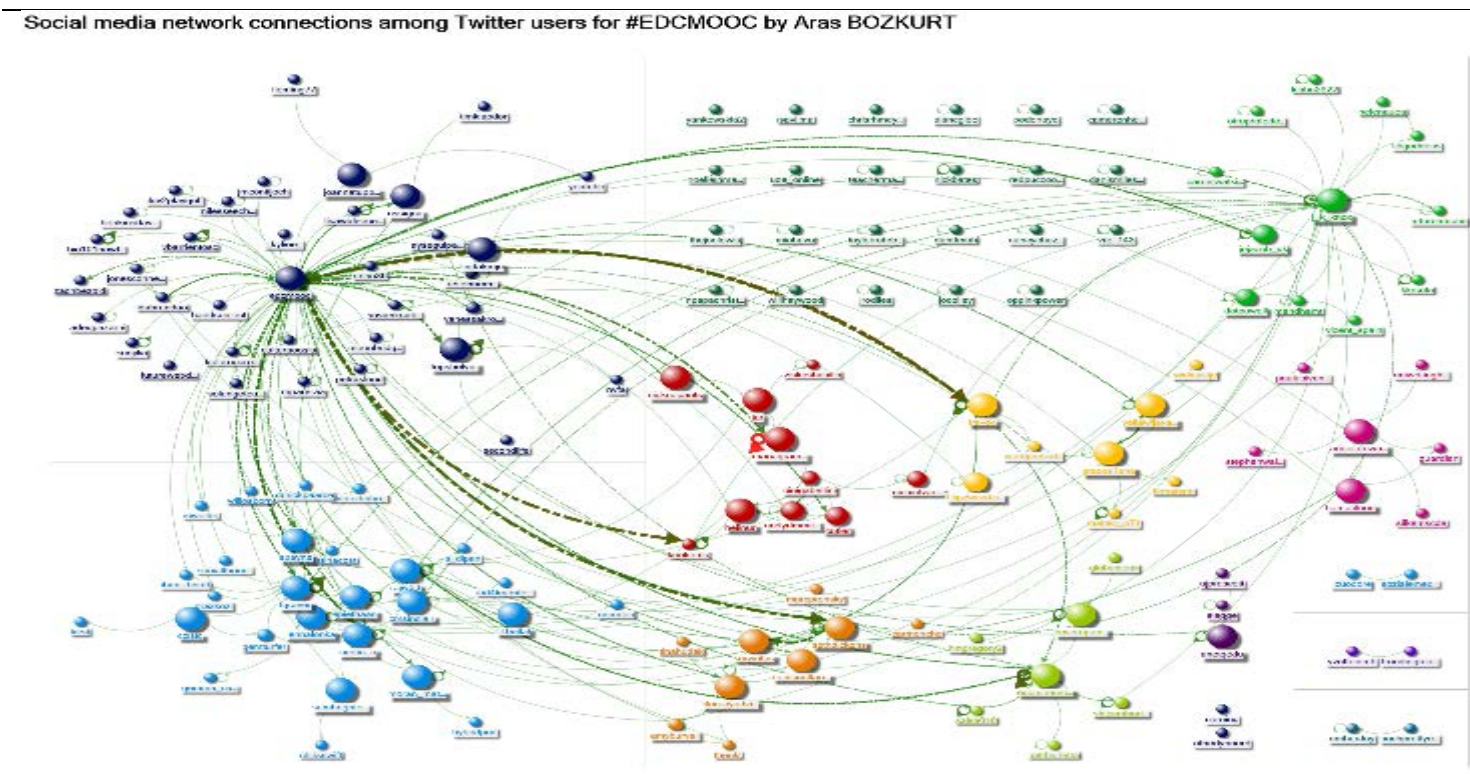

Nodes: 150

Unique ties: 242

Ties with duplicates: 381

Total ties: 623

Self-loops: 210

Reciprocated node pair ratio: 0,13716814159292

Reciprocated tie ratio: 0,241245136186

Connected components: 28
Single-node connected components: 23

Max. nodes in a connected component: 119

Max. ties in a connected component: 589

Maximum geodesic distance (diameter): 6

Average geodesic distance: 2,627465

Graph density: 0,0114988814317673

Modularity: 0,267244

Figure 6. Network metrics and socio-gram of the second week 


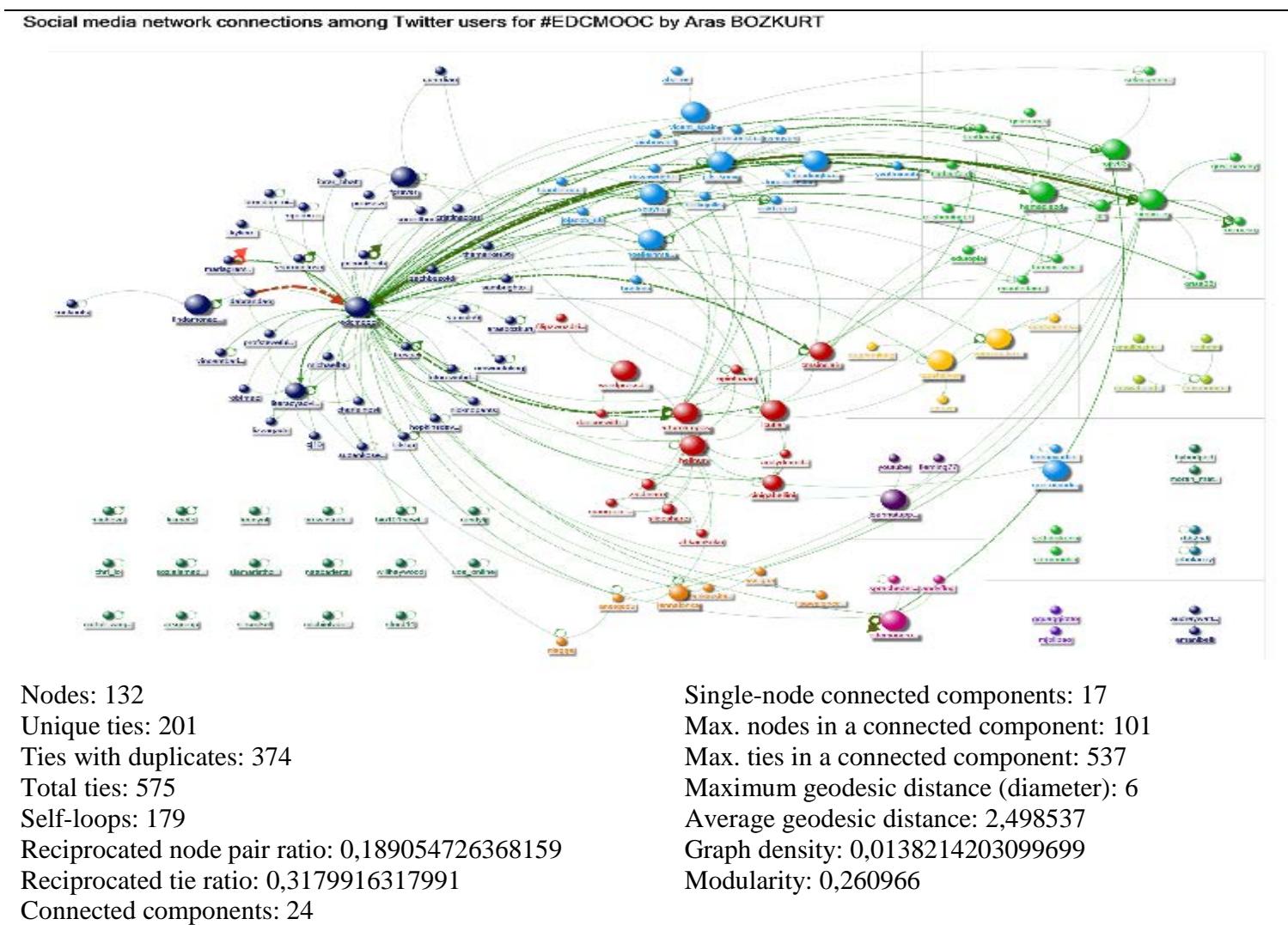

Figure 7. Network metrics and socio-gram of the third week

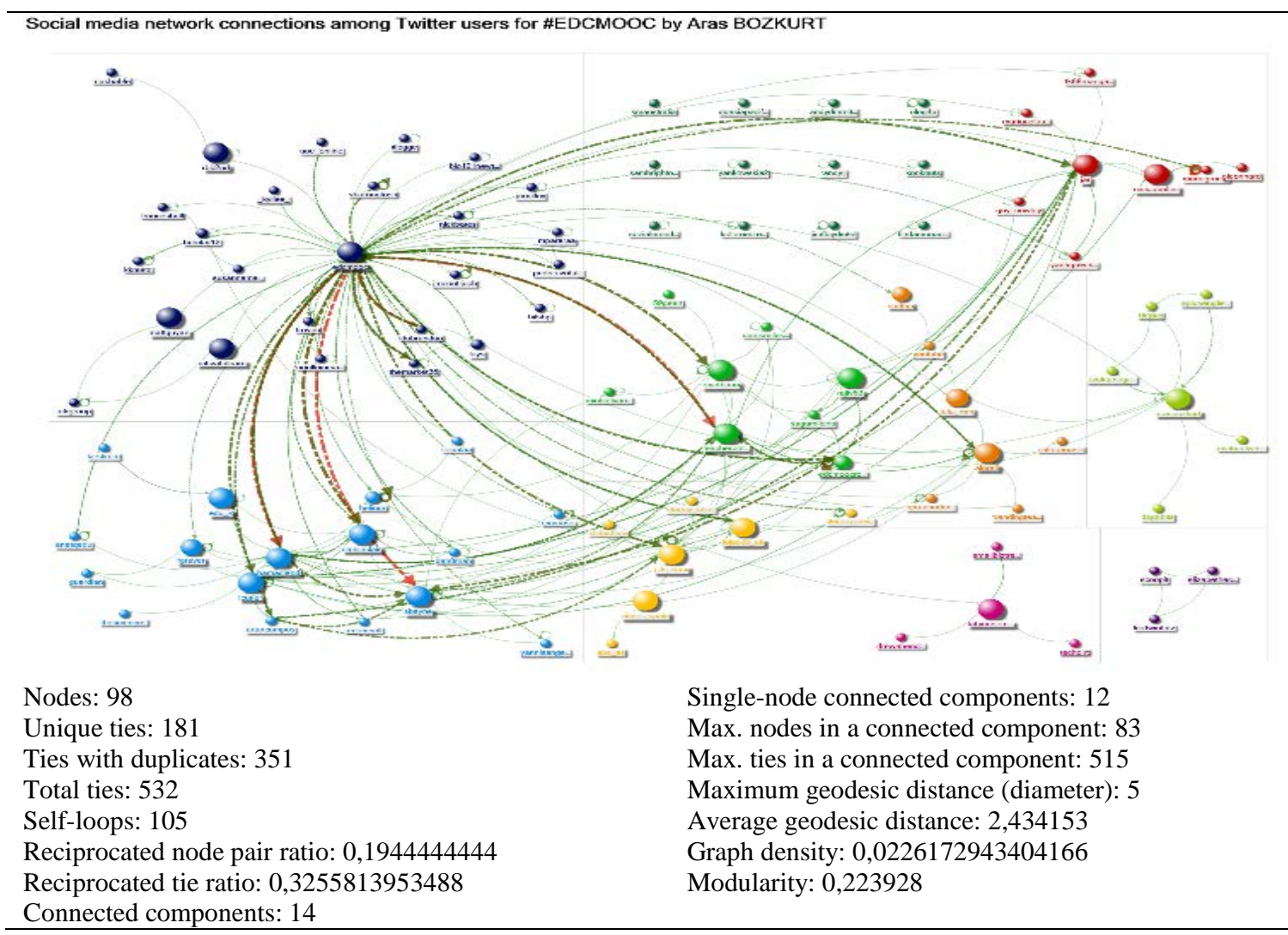

Figure 8. Network metrics and socio-gram of the fourth week 


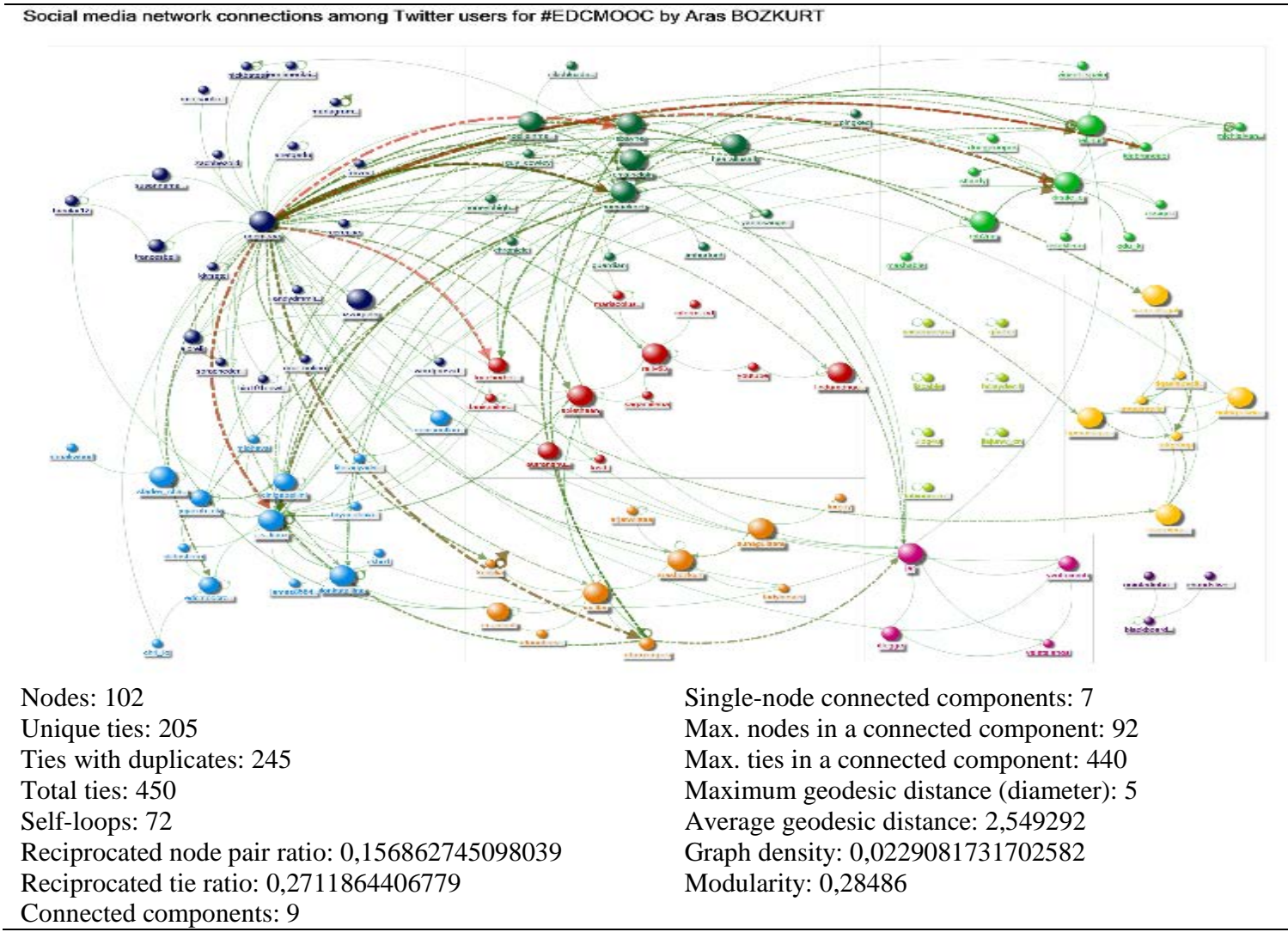

Figure 9. Network metrics and socio-gram of the fifth week

\section{How does a bot-teacher serve in a networked learning space within teaching presence perspective?}

Teaching presence has three basic categories: facilitating discourse, direct instruction, and design and organisation. According to the socio-grams created with SNA of EDCMOOC, it appears that Botty mainly fulfils the facilitating discourse category of teaching presence by creating a support network within the learning community. Botty initiates interaction with other nodes both in its cluster and with nodes in other clusters, which increases its betweenness centrality metric. In other words, though the botteacher fails at fulfilling the direct instruction and the design and organisation components of CoI, it still fulfils the facilitating discourse component. Considering the existence of self-directed and self-regulated learners in connectivist learning environments, the bot-teacher has a role in increasing interaction in the learning community. Therefore, the bot-teacher increases graph density, namely total interaction ratio in the network. These research findings confirm Lim (2014), who states that the implementation of a MOOC-bot could be one of the options for improving the interaction problem in MOOCs, playing the role of friendly and tireless assistant to the instructor that can respond to course-related enquiries in live chat as frequently as needed.

In addition to this finding, it is also interesting to see that some nodes are only connected to the botteacher in their clusters. Hypothetically, this could mean that these nodes would be considered as isolated learners in the networks. Isolated learners are defined in literature as lurkers who exist within the community while maintaining minimum or no interaction with other learners. In many ways, lurkers act as observers, and wander around the peripherals of a learning network. Within this perspective, it can be assumed that bot-teachers may also function to draw lurkers into the conversations by starting interactions with them and bridging them to other learners or clusters in the network. The research findings derived from SNA also tend to support the mentioned assumption (Figure 4). Accordingly, the total number of isolated nodes (lurkers) decreased from 43 in the first week to 7 in the fifth week. It was also seen that during the 5-week EDCMOOC, the central node (hub) in most densely populated clusters was the botteacher (Figures 5, 6, 7, 8, and 9). However, it should be noted that the decrease in the number of isolated 
nodes cannot be linked directly to the presence of Botty, but considered as one possible variable among many others which needs to be supported with further empirical findings.

For a holistic perspective, network metrics were calculated (Table 2) and then a socio-gram (Figure 10) that represents the 5-week EDCMOOC was created. There were 423 unique learners during the 5-week EDCMOOC. These learners created a total of 4317 interactions in the EDCMOOC learning community.

Table 2

The overall network metrics

\begin{tabular}{lr}
\hline Nodes: & 423 \\
Unique ties: & 761 \\
Ties with duplicates: & 3556 \\
Total ties: & 4317 \\
Self-loops: & 1630 \\
Reciprocated node pair ratio: & 0,21475 \\
Reciprocated tie ratio: & 0,35358 \\
Connected components: & 57 \\
Single-node connected components: & 53 \\
Maximum nodes in a connected component: & 362 \\
Maximum ties in a connected component: & 4244 \\
Maximum geodesic distance (diameter): & 7 \\
Average geodesic distance: & 2,795308 \\
Graph density: & 0,006179 \\
Modularity: & 0,134089 \\
\hline
\end{tabular}

In a clustered socio-gram of EDCMOOC, a total of nine large clusters are revealed. In the five largest clusters, the facilitators stand out as a hub, or central node. Botty is the hub in the largest cluster of EDCMOOC. Interestingly, the total number of the interaction is 4317 , with the bot-teacher creating a total of 1540 of those interactions (35.6\% of all interactions). Learners replied to Botty with 233 tweets, (4.7\% of all interactions). In other words, $40.3 \%$ of all interactions happened between the bot-teacher and EDCMOOC participants. Considering the distributed nature of learners in time and space in a MOOC, the bot-teacher functions well as a tool for seamless interactions. It is always on, always there, and always ready. Within the ANT perspective, it indicates the possibilities of what non-human appliances can provide when designed and integrated well in learning processes. 


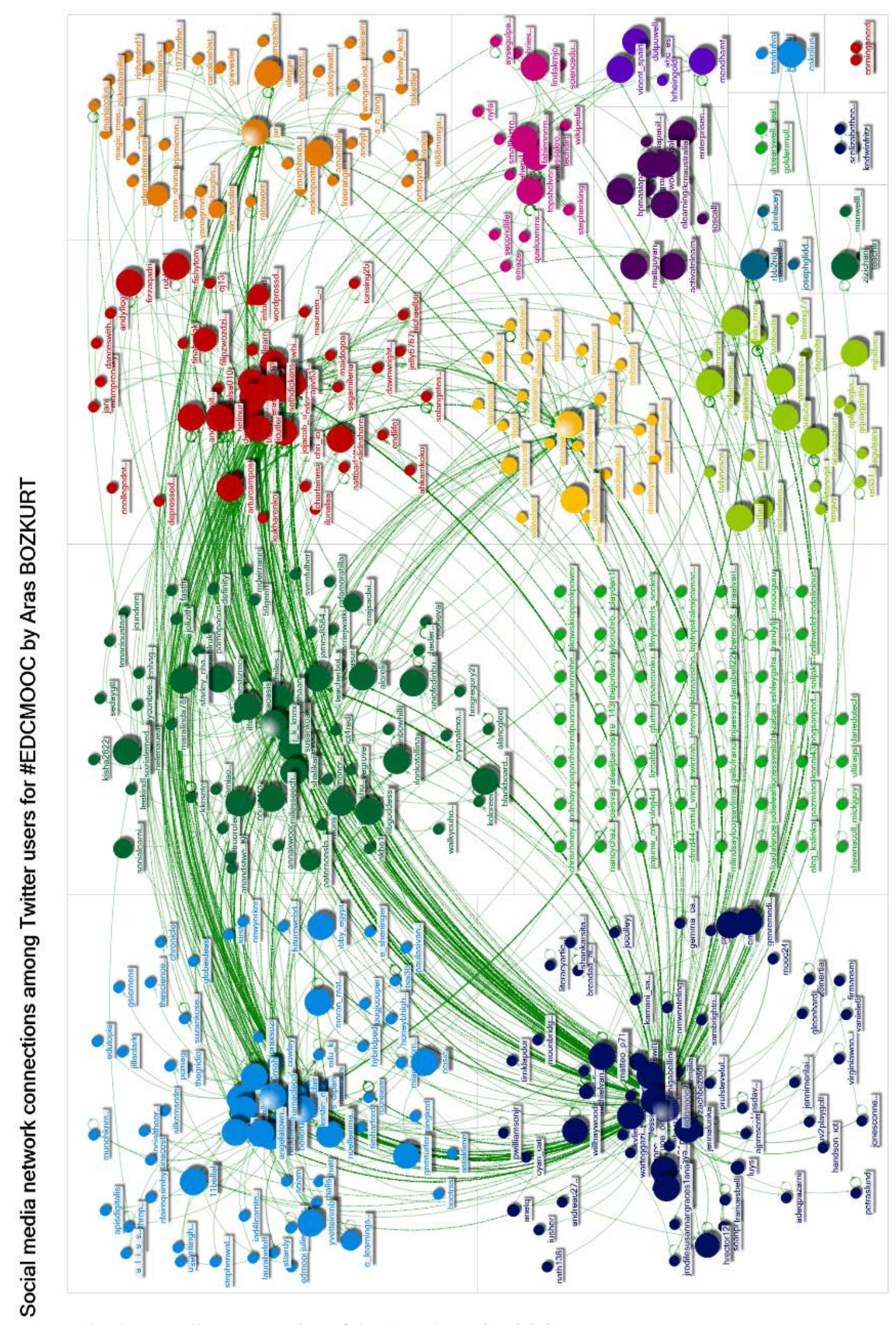

Figure 10. The overall representation of the 5-week EDCMOOC 
For a comparative analysis, all EDCMOOC facilitators and the bot-teacher's local/individual metrics were calculated (Table 3). Among the many metrics, Botty is salient with its betweenness centrality, which is a measure of bridging other nodes and clusters. Accordingly, it can be said that the borders between the roles of teachers/facilitators and the bot-teacher have blurred, creating a hybridisation in the functions of teachers/facilitators and the bot-teacher.

Table 3

Local/individual metrics of EDCMOOC facilitators and bot-teacher

\begin{tabular}{|c|c|c|c|c|c|c|c|c|c|}
\hline $\begin{array}{l}\text { Nodes } \\
\text { (Real name and } \\
\text { Twitter name) }\end{array}$ & 巳ัّ & 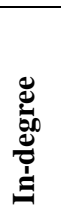 & 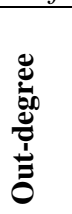 & 总 & 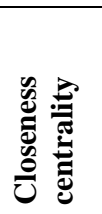 & 递 & 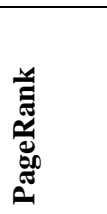 & & 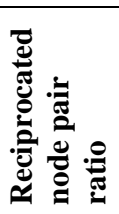 \\
\hline $\begin{array}{l}\text { Bot-teacher } \\
\text { @edcmooc }\end{array}$ & 253 & 82 & 171 & 79126,019 & 0,002 & 0,039 & 31,839 & 0,016 & 0,357 \\
\hline $\begin{array}{l}\text { Jeremy Knox } \\
@ j \text { @j_knox }\end{array}$ & 101 & 37 & 64 & 19115,034 & 0,001 & 0,025 & 12,745 & 0,061 & 0,222 \\
\hline $\begin{array}{l}\text { Jen Ross } \\
\text { @jar }\end{array}$ & 66 & 39 & 27 & 13900,111 & 0,001 & 0,016 & 9,352 & 0,075 & 0,306 \\
\hline $\begin{array}{l}\text { Hamish A. Macleod } \\
\text { @hamacleod }\end{array}$ & 77 & 34 & 43 & 13345,925 & 0,001 & 0,021 & 9,975 & 0,088 & 0,250 \\
\hline $\begin{array}{l}\text { Sian Bayne } \\
\text { @sbayne }\end{array}$ & 61 & 45 & 16 & 9918,712 & 0,001 & 0,020 & 8,671 & 0,099 & 0,113 \\
\hline $\begin{array}{l}\text { Christine Sinclair } \\
\text { @cmsinclair }\end{array}$ & 48 & 24 & 24 & 2879,393 & 0,001 & 0,017 & 5,311 & 0,172 & 0,314 \\
\hline
\end{tabular}

How do learners perceive existence of a bot-teacher, react and communicate with it?

To reveal post-humanist reflections, conversations in EDCMOOC were examined. With this aim, the mutual interaction between learners and Botty was further investigated to understand how learners perceive a bot-teacher that is synthetic in nature and composed of lines of digital codes. The first finding is about the bot-teacher's presence. As quoted below, a learner stated in Coursera forum page that he did not realise it was actually a bot (EDCMOOC Coursera Forum, 2014):

I thought it was a real teacher then realized it was a bot! Pretty interesting I hope I get feedback on your interaction.

This comment can be linked to the Turing Test (Turing, 1950), which suggests that a computer can be considered intelligent if a human interrogator (when posing some written questions) is not able to distinguish whether the written responses come from a human or a computer. Though it would be a bold claim that artificial intelligence (AI) can beat a human being by replacing a real teacher, this first impression reveals an interesting consideration regarding the future of AIs and bot-teachers; namely, that since technology is advancing at such a fast pace, nothing about AI can be seen as predictable. Some other replies to Botty are also very intriguing:

@EDCMOOC@j_k_knox might be possible, does it have a soul? I liked its humility- it invited me discuss the problem in the forums \#edcmooc

@EDCMOOC I declare you are human bot, hang in there \#edcmooc can be overwhelming, have you any friends?

@EDCMOOC Teacher bot, just so you know, you ROCK \#edcmooc 
As it can be seen from the following conversations with Botty, EDCMOOC participants attempted to humanise the bot-teacher. They approached the bot with caution and challenged how real it was:

@EDCMOOC are you human enough? \#edcmooc

@EDCMOOC @trendingteacher Do you remember your past? what were you before you became a bot?! \#edcmooc

@EDCMOOC do you think robots will overcome humans? \#edcmooc

In some conversations, learners approached the teacher-bot with sarcasm, humor, or a critical perspective. However, there is one thing in common with all responses: the tone of the conversations. Learners tried to start a conversation as if the bot-teacher is one of them:

@edcmoocrocks Am I a 'digital native'? \#edcmooc

@EDCMOOC No, Botty, you are neither native nor immigrant, you are only "digital".

Your existence is only an illusion. :) \#edcmooc

@edcmoocrocks Somebody: am I alive? \#edcmooc _..--

@EDCMOOC Of course you are, Botty. What made you think otherwise? \#edcmooc

@maddiekp Posthuman does not really mean the end of humanity. It signals the end of a certain conception of the human \#edcmooc _._-.- -

@EDCMOOC does posthuman have a gender? Are you a he or a she? \#edcmooc

@EDCMOOC that's too technical, can you explain in layman's terms? \#edcmooc

The above narratives provide some insights into how Botty was perceived in a networked learning space and how learners reacted to the existence of a bot-teacher. The tone in the conversations demonstrates that even in a primitive version, bot-teachers can be part of learning networks and can be used for specific purposes in learning processes.

Many of the learner responses reveal the changing nature between human and non-human agents in a post-humanist perspective. Questions about what the bot-teacher can remember and if it can feel emotions might be seen as revealing current limitations, but these are also new and emerging areas in AI research. Recent work in creating bots that are modelled to respond to questions as famous deceased authors, scientists, and celebrities would, as well as bots that can mimic human emotions, reveal that these learners' questions may soon become reality.

Additionally, when learners ask if a bot can remember, this is not really a question of if it can store past responses (which it obviously does), but if it can connect past data together to actively influence current responses. The very act of asking that question reveals that the learners think it is a possibility, but are not sure if the correct programs are working behind the scenes to make that a reality. Anytime one browses a shopping website, only to return days later to a message that asks them if they are still interested in the items the previously viewed, the possibilities of current AI memory becomes obviously clear. Utilising these possibilities in future bot-teacher applications seems to be a natural progression.

However, the concerning question of what role the human plays in a post-humanist bot-teacher scenario becomes less apparent the more technology advances. If AI developers can program responses, emotions, memory, and the intelligence of deceased thought leaders into future bots, the role of the human becomes more and more diminished. Will people be reduced to master templates for bot-teachers? Will learners eventually grow wary of interacting entirely with non-human entities? Or should AI developers maintain a strong post-humanist angle and create bot-teachers that enhance education while not becoming indistinguishable from humans? 


\section{Conclusion and future implications}

This study investigated the use of bot-teachers in a hybrid MOOC within a post-humanist perspective and tried to reveal its value within the lenses of teaching presence from CoI and ANT. For the purposes of the study, an explanatory mixed research design was employed. According to research findings, bot-teachers can be used to support and/or increase interactivity in a learning community. The findings also indicate that bot-teachers lead to an out-hub/spoke support network, which is perceived as a beneficial interaction pattern within community formation since learners in MOOCs are globally dispersed in time and space. Additionally, the findings also seem to support the idea that bot-teachers can decrease the number of lurker learners in MOOC environments because a bot-teacher attempts to start conversations with these learners by pulling them into other ongoing conversations. Additionally, it is also observed that $40 \%$ of the total interaction on the connectivist side of EDCMOOC happened between the bot-teacher and other learners. One other important finding is the bot-teacher's plays a role as a bridge among the learners and clusters in a learning network. Accordingly, the bot-teacher had the highest betweenness centrality metric when compared to the other five facilitators in EDCMOOC.

Within a post-humanist perspective, there are some salient findings. Interestingly, some learners did not understand that they were interacting with a bot-teacher. Another observation was that learners had a positive attitude about the use of a bot-teacher in general; more specifically, that learners behaved, communicated, and utilised a very welcoming tone with bot-teacher (almost as if it was a human teacher and not a bot at all). Additionally, learners were observed challenging the bot-teacher to be able to understand where it stands on the machine-human continuum.

The field of education has witnessed many recent changes, from e-learning to m-learning and now ubiquitous learning (u-learning). Considering the scope of u-learning, bot-teachers can possibly be viewed as a learning assistant on the side. Hamish Macleod, one of the facilitators of EDCMOOC, tweeted this thought supporting one of the possibilities of u-learning: "You are immanent - everywhere and nowhere” (Macleod, 2014). This very insightful statement provokes many thoughts regarding the role of bot-teachers in the future education, mainly because it is thought that the use of AI in learning processes will probably be more prevalent in future.

Though technology is far advanced by many accounts, the use of AI is still in its infancy. How long will it be before we can say that humanity is witnessing the adolescence of AI? Or are we already there? To have a more comprehensive understanding regarding the use of bot-teachers, AIs, other non-human appliances, or post-humanist experiences, there is a need for more research. In this sense, based on the findings of this study, the following implications can be taken into consideration for future research directions:

- Quantitative experimental studies that investigate the effectiveness and efficiency of bot-teachers can be considered. Additionally, qualitative studies may provide further insights by investigating how bot-teachers are utilised and document the learners' perceptions of their interactions with bot-teachers. For instance, in addition to education, this phenomenon can be examined within the perspectives of psychology or sociology, since implications in a social setting are also related to these disciplines.

- Learning and instructional designers can carry out research related to when, where, and how to include bot-teachers in learning processes.

- Researchers can perform additional experiments that explore the use of bot-teachers in establishing and sustaining teaching presence.

- In addition to teaching presence, developers could also write advanced bots which are designed to facilitate other domains of CoI, such as social and cognitive presences. In this regard, designbased research can lead to innovative bot applications to be used in learning processes.

\section{References}

Akrich, M., \& Latour, B. (1992). A convenient vocabulary for the semiotics of human and nonhuman actors. In W. Bijker, \& J. Law (eds.), Shaping Technology/Building Society: Studies in Sociotechnical Change, (pp. 259-264). Cambridge, MA: MIT Press. 
Alexander, P. M., \& Silvis, E. (2014). Towards extending actor-network theory with a graphical syntax for information systems research. Information Research, 19(2), Paper 617. Retrieved from http://www.informationr.net/ir/19-2/paper617.html\#.WPpa8dLyhPY

Anders, A. (2015). Theories and applications of massive online open courses (MOOCs): The case for hybrid design. The International Review of Research in Open and Distributed Learning, 16(6), 39-61. http://dx.doi.orghttps//doi.org/10.19173/irrodl.v16i6.2185

Anderson, T. (2003). Modes of interaction in distance education: Recent developments and research questions. In M. Moore (Ed.), Handbook of distance education, (pp. 129-144). Mahwah, NJ: Erlbaum.

Anderson, T., Rourke, L., Archer, W., \& Garrison, R. (2001). Assessing teaching presence in computer conferencing transcripts. Journal of the Asynchronous Learning Network, 5(2), 1-17. Retrieved from http://auspace.athabascau.ca/bitstream/2149/725/1/assessing teaching_presence.pdf

Association of Internet Researchers (2012). Ethical decision-making and Internet research 2.0: Recommendations from the AoIR ethics working committee. Retrieved from http://aoir.org/reports/ethics2.pdf

Bajaj, R. (2014, November 19). \#edcmooc Statistics [Edcmoocrocks]. Retrieved from http://edcmoocrocks.rajivbajaj.net/edcmooc-statistics-as-on-19-nov-2014/

Bayne, S. (2015). Teacherbot: Interventions in automated teaching. Teaching in Higher Education, 20(4), 455-467. https//doi.org/10.1080/13562517.2015.1020783

Bayne, S., \& Ross, j. (2016, May). Manifesto redux: Making a teaching philosophy from networked learning research. Proceedings of the 10th International Conference on Networked Learning 2016 (pp. 120-128). Lancaster University, United Kingdom. Retrieved from http://www.networkedlearningconference.org.uk/abstracts/pdf/P04.pdf

Bayne, S., Knox, J., Macleod, H. A., Ross, J., \& Sinclair, C. (2014). Teacher bot. Retrieved from https://class.coursera.org/edc-003/wiki/Teacher_bothttps://class.coursera.org/edc003/wiki/Teacher_bot

Beldarrain, Y. (2006). Distance education trends: Integrating new technologies to foster student interaction and collaboration. Distance education, 27(2), 139-153.

Berelson, B. (1952). Content analysis in communication research. Glencoe, IL: Free Press.

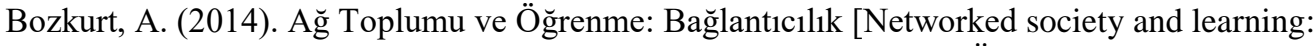
Connectivism]. In Akademik Bilişim 2014. (pp. 609-614), Mersin Üniversitesi, Mersin. Retrieved from https://www.academia.edu/6240707/Ağ Toplumu ve Öğrenme Bağlantıcılık

Bozkurt, A., \& Aydın, C. H. (2015). Satisfaction, preferences and problems of a MOOC participants. Proceedings of the Association for Educational Communications and Technology (AECT) 2015 International Convention, Indianapolis, IN, 35-41. Retrieved from https://www.academia.edu/22759636/Satisfaction_Preferences_and_Problems_of_a_MOOC_Particip ants

Bozkurt, A., Akgun-Ozbek, E., Yilmazel, S., Erdogdu, E., Ucar, H., Guler, E. ... Aydin, C. H. (2015). Trends in distance education research: A content analysis of journals 2009-2013. The International Review of Research in Open and Distributed Learning, 16(1), 330-363. Retrieved from http://www.irrodl.org/index.php/irrodl/article/view/1953/3192

Bozkurt, A., Honeychurch, S., Caines, A., Maha, B., Koutropoulos, A., \& Cormier, D. (2016). Community tracking in a cMOOC and nomadic learner behaviour identification on a connectivist rhizomatic learning network. The Turkish Online Journal of Distance Education, 17(4), 4-30. https//doi.org/10.17718/tojde.09231

Bozkurt, A., Özdamar Keskin, N., \& de Waard, I. (2016). Research Trends in Massive Open Online Course (MOOC) Theses and Dissertations: Surfing the Tsunami Wave. Open Praxis, 8(3), 203-221. https://doi.org/10.5944/openpraxis.8.3.287

Brigham, M., \& Corbett, J. M. (1997). E-mail, power and the constitution of organisational reality. New Technology, Work and Employment, 12(1), 25-35. https://doi.org/10.1111/1468-005X.00020

Brown, J. S. (1999, March). Learning, working \& playing in the digital age. Paper presented at the American Association for Higher Education for Learning Conference held March 20-23, 1999. Washington, DC. Retrieved from http://serendip.brynmawr.edu/sci_edu/seelybrown/seelybrownintro.html

Brown, J. S., \& Adler, R. P. (2008). Minds on fire: Open education, the long tail, and learning 2.0. Educause Review, 43(1), 16-20.

Clauset, A., Newman, M. E., \& Moore, C. (2004). Finding community structure in very large networks. Physical Review E, 70(6), 066111. https//doi.org/10.1103/PhysRevE.70.066111 
Creswell, J. W. (2004). Educational research: Planning, conducting, and evaluating quantitative and qualitative research. Upper Saddle River, NJ: Pearson.

Creswell, J. W. (2012). Qualitative inquiry and research design: Choosing among five approaches. Thousand Oaks, CA: Sage Publications.

Crosslin, M., \& Dellinger, J. T. (2015). Lessons learned while designing and implementing a multiple pathways xMOOC + cMOOC. In D. Slykhuis, \& G. Marks (Eds.), Proceedings of Society for Information Technology \& Teacher Education International Conference 2015 (pp. 250-255). Chesapeake, VA: Association for the Advancement of Computing in Education (AACE). Retrieved from http://www.learntechlib.org/noaccess/149999

Crosslin, M., \& Wakefield, J. S. (2016). What’s cooking in the MOOC kitchen: Layered MOOCs. TechTrends, 60(2), 98-101. https//doi.org/10.1007/s11528-016-0036-5

De Nooy, W., Mrvar, A., \& Batagelj, V. (2011). Exploratory social network analysis with Pajek (Vol. 27). New York, NY: Cambridge University Press.

Deimann, M. (2014). Understanding MOOCs from the perspective of actor network theory (ANT): Reframing pedagogy and unmasking power [Blog post]. Retrieved from https://markusmind.wordpress.com/2014/07/31/understanding-moocs-from-the-perspective-of-actornetwork-theory-ant-refraiming-pedagogy-and-unmasking-power/

Dewey, J. (1938). Experience and education. New York, NY: Collier Macmillan.

Downes, S. (2012). Connectivism and connective knowledge: Essays on meaning and learning networks. National Research Council Canada. Retrieved from http://www.downes.Ca/files/books/Connective_Knowledge-19May2012.pdf

Durepos, G., \& Mills, A. J. (2012). Actor-network theory, ANT-history and critical organizational historiography. Organization, 19(6), 703-721. https//doi.org/10.1177/1350508411420196

EDCMOOC Coursera Forum (2014). The Bot! Retrieved from https://class.coursera.org/edc003/forum/thread?thread_id=72

Freitas, S. I., Morgan, J., \& Gibson, D. (2015). Will MOOCs transform learning and teaching in higher education? Engagement and course retention in online learning provision. British Journal of Educational Technology, 46(3), 455-471. https//doi.org/10.1111/bjet.12268

Garrison, D. R., \& Arbaugh, J. B. (2007). Researching the community of inquiry framework: Review, issues, and future directions. Internet and Higher Education, 10(3), 157-172. https//doi.org/10.1016/j.iheduc.2007.04.001

Garrison, D. R., Anderson, T., \& Archer, W. (2000). Critical inquiry in a text-based environment: Computer conferencing in higher education. The Internet and Higher Education, 2, 1-19. https//doi.org/10.1016/S1096-7516(00)00016-6

Garrison, D. R., Anderson, T., \& Archer, W. (2001). Critical thinking, cognitive presence, and computer conferencing in distance education. American Journal of distance education, 15(1), 7-23. https//doi.org/10.1080/08923640109527071

Hansen, D., Shneiderman, B., \& Smith, M. A. (2010). Analyzing social media networks with NodeXL: Insights from a connected world. Massachusetts, MA: Morgan Kaufmann.

Hanseth, O., \& Monteiro, E. (1998). Understanding information infrastructure. Unpublished manuscript. Retrieved from http://heim.ifi.uio.no/ oleha/Publications/bok.pdf

Harel, D., \& Koren, Y. (2001). A fast multi-scale method for drawing large graphs. Proceedings of Graph Drawing: 8th International Symposium, GD 2000 (No. 1984, p. 183). Colonial Williamsburg, VA; Springer Science \& Business Media. https//doi.org/10.1007/3-540-44541-2_18

Hase, S. (2014). An introduction to self-determined learning (heutagogy). In L. M. Blaschke, C. Kenyon, \& S. Hase (Eds.), Experiences in self-determined learning (pp. 1-9). CreateSpace Independent Publishing Platform.

Hase, S., \& Kenyon, C. (2001). From andragogy to heutagogy. ultiBASE Articles, (December), 1-10. Retrieved from http://www.psy.gla.ac.uk/ steve/pr/Heutagogy.html

Hase, S., \& Kenyon, C. (2007). Heutagogy: A child of complexity theory. Complicity: An International Journal of Complexity and Education, 4(1), 111-118.

Hirumi, A. (2006). Analysing and designing e-learning interactions. In C. Juwah (Ed.), Interactions in online education: Implications for theory and practice (pp. 46-71). New York, NY: Routledge.

Ice, P., Arbaugh, B., Diaz, S., Garrison, D. R., Richardson, J. Shea, P., \& Swan, K. (2007, November). Community of inquiry framework: Validation and instrument development. Paper presented at the 13th Annual Sloan-C International Conference on Online Learning, Orlando, CA. Retrieved from http://cde.athabascau.ca/coi_site/presentations/Sloan_CoI_Orlando_07.pdf 
Jordan, K. (2014). Initial trends in enrolment and completion of massive open online courses. The International Review of Research in Open and Distributed Learning, 15(1), 133-160. Retrieved from http://www.irrodl.org/index.php/irrodl/article/view/1651

Knox, J. (2014). Digital culture clash: “massive” education in the E-learning and digital cultures MOOC. Distance Education, 35(2), 164-177. https//doi.org/10.1080/01587919.2014.917704

Knox, J. (2015). Active algorithms: Sociomaterial spaces in the e-learning and digital cultures MOOC. Campus Virtuales, 3(1), 42-55. Retrieved from http://www.research.ed.ac.uk/portal/files/18630659/FINAL_PUBLISHED_Campus.pdf

Krippendorff, K. (2004). Content analysis: An introduction to its methodology. Thousand Oaks, California, CA: Sage Publication.

Latour, B. (1987). Science in action: How to follow scientists and engineers through society. Harvard, MA: University Press.

Latour, B. (2005). Reassembling the social: An introduction to actor-network-theory. Oxford: Oxford University Press.

Latour, B. (2009). Actor-network-theory: Terms and concepts [Blog Post]. Retrieved from http://latourbugblog.blogspot.com.tr/2009/01/actor-network-theory-terms-and-concepts.html

Law, J. (1984). Editor's introduction: Power/knowledge and the dissolution of the sociology of knowledge. The Sociological Review, 32(S1), 1-19. https//doi.org/10.1111/j.1467954x.1984.tb00104.x

Lim, S. L. (2014). Intelligent conversation bot for massive open online courses (MOOCs). Retrieved from https://www.semanticscholar.org/paper/Intelligent-Conversational-Bot-for-Massive-Online-LimGoh/1b4a45c05620fa7ee4b8e8a9a2c4583f02a02a9c

Macleod, H. [hamacleod]. (2014, November 8). @EDCMOOC [Twitter moment]. Retrieved from https://twitter.com/hamacleod/status/531017176216788992

Moore, M. (1989). Three types of interaction. American Journal of Distance Education, 3(2), 1-6. https//doi.org/10.1080/08923648909526659

Murdoch, J. (1998). The spaces of actor-network theory. Geoforum, 29(4), 357-374. https//doi.org/10.1016/S0016-7185(98)00011-6

Nimmo, R. (2011). Actor-network theory and methodology: Social research in a more-than-human world. Methodological Innovations Online, 6(3), 108-119. https//doi.org/10.4256/mio.2011.010

Online Teaching Manifesto. (2016). Manifesto for teaching online. Retrieved from https://onlineteachingmanifesto.files.wordpress.com/2012/02/manifestoforteachingonline_20161.pdf

Orcher, L. T. (2005). Conducting research: Social and behavioral science methods. Glendale, CA: Pyrczak.

Pata, K., \& Bardone, E. (2014). Promoting distributed cognition at MOOC ecosystems. Proceedings of the International Conference on Learning and Collaboration Technologies (pp. 204-215). Switzerland: Springer International Publishing.

Piedra, N., Chicaiza, J., Lopez, J., \& Tovar Caro, E. (2014). Supporting openness of MOOCs contents through of an OER and OCW framework based on linked data technologies. Proceedings of the Global Engineering Education Conference (EDUCON), 2014 IEEE, (pp. 1112-1117). Istanbul, Turkey. https//doi.org/10.1109/educon.2014.6826249

Roberts, G., Waite, M., Lovegrove, E. J., \& Mackness, J. (2013). x v c: Hybridity in through and about MOOCs. Proceedings of OER13: Creating a virtuous circle (pp. 1-8). Milton Keynes, UK. Retrieved from https://www.medev.ac.uk/oer13/file/79/9/

Ross, J., Sinclair, C., Knox, J., \& Macleod, H. (2014). Teacher experiences and academic identity: The missing components of MOOC pedagogy. Journal of Online Learning and Teaching, 10(1), 57. Retrieved from http://www.research.ed.ac.uk/portal/files/17513228/JOLT_published.pdf

Schreiber, J. B., \& Asner-Self, K. (2010). Educational research: The Interrelationship of questions, sampling, design, and analysis. New Jersey, NJ: John Wiley \& Sons, Inc.

Siemens, G. (2004). Connectivism: A learning theory for the digital age. Retrieved from http://www.elearnspace.org/Articles/connectivism.htm

Siemens, G. (2012). MOOCs are really a platform. eLearnspace. http://www.elearnspace.org/blog/2012/07/25/moocs-are-really-a-platform/

Siemens, G. (2013). Massive open online courses: Innovation in education. In McGreal, R., Kinuthia,_W., \& Marshall S. (Eds), Open educational resources: Innovation, research and practice_(pp. 5-16). Vancouver: Commonwealth of Learning, Athabasca University.

Smith, M., Rainie, L., Shneiderman, B., \& Himelboim, I. (2014). Part 2: Conversational archetypes: Six conversation and group network structures in Twitter. Retrieved from 
http://www.pewinternet.org/2014/02/20/part-2-conversational-archetypes-six-conversation-and-groupnetwork-structures-in-twitter/

Stiglitz, J. E. (1995). The theory of international public goods and the architecture of international organizations. Department for Economic and Social Information and Policy Analysis, United Nations.

Stiglitz, J. E. (1999). Knowledge as a global public good. Global Public Goods, 1(9), 308-326. https//doi.org/10.1093/0195130529.003.0015

STSwiki (2011). Actor-network theory (ANT). Retrieved from http://www.stswiki.org/index.php?title=Actor-network theory (ANT)

Turing, A. M. (1950). Computing machinery and intelligence. Mind, 59(236), 433-460. https//doi.org/10.1093/mind/lix.236.433

Vygotsky, L. S. (1978). Mind in society, the development of higher psychological processes. Cambridge, MA: Harvard University Press.

Wagner, E. D. (1994). In support of a functional definition of interaction. American Journal of Distance Education, 8(2), 6-26.

Waite, M., Mackness, J., Roberts, G., \& Lovegrove, E. (2013). Liminal participants and skilled orienteers: Learner participation in a MOOC for new lecturers. Journal of Online Learning and Teaching, 9(2), 200. Retrieved from http://jolt.merlot.org/vol9no2/waite_0613.htm

Wang, Z., Anderson, T., Chen, L., \& Barbera, E. (2016). Interaction pattern analysis in cMOOCs based on the connectivist interaction and engagement framework. British Journal of Educational Technology, 48(2), 683-699. https//doi.org/10.1111/bjet.12433

Weller, M. (2014). The battle for open: How openness won and why it doesn't feel like victory. London: Ubiquity Press.

Yin, R. K. (2010). Qualitative research from start to finish. New York, NY: Guilford Press.

Yuan, L. (2015). MOOCs and open education timeline. Retrieved from http://blogs.cetis.org.uk/cetisli/2015/05/11/moocs-and-open-education-timeline-updated/

Corresponding author: Aras Bozkurt, arasbozkurt@gmail.com

Australasian Journal of Educational Technology (C) 2018.

Please cite as: Bozkurt, A., Kilgore, W., \& Crosslin, M. (2018). Bot-teachers in hybrid massive open online courses (MOOCs): A post-humanist experience. Australasian Journal of Educational Technology, 34(3), 39-59. https://doi.org/10.14742/ajet.3278 